\section{Commentary: Which came first, the chylothorax or the thrombus?}

\author{
David Bichell, MD
}

Some of the unclarity surrounding postoperative chylothorax lies in the heterogeneity of pathways that produce identical observations of chylous effusion and the reality that one treatment plan does not fit all. If chylothorax cases could be accurately categorized into thoracic duct injury (less common), extrinsic obstructive force (thrombosis), or intrinsic lymphatic pathology, then pathophysiologyspecific protocols for management could expect improved success. Diagnostic limitations and circular associations of cause and effect continue to cloud the understanding of the etiology, risk calculation, and treatment.

Corda and colleagues, ${ }^{1}$ in the current issue of the Journal, postulate that propranolol acts on intrinsically abnormal lymphatic endothelial cells to reduce leak. The authors include an excellent review of the emerging understanding of the interrelationship of lymphatic and cardiac dysmorphogenesis and the physiology of lymphatic flow disorder. Twenty-five pediatric cardiac patients with chylothorax were treated with propranolol, and data were compared with historic controls. Fifteen patients were "responders," enjoying an $80 \%$ reduction in chylous output within 10 days of the start of treatment. Morbidities such as venous thrombosis and infection, presumed from chylous fluid loss, occurred less in the responder group.

\section{CHYLOTHORAX AS A CONSEQUENCE OF INTRINSIC LYMPHATIC ABERRATION}

Corda and colleagues ${ }^{1}$ shine important light on chylothorax as a consequence of intrinsic lymphatic pathology and translate laboratory findings into a therapeutic approach that deserves attention. Even so, delay in diagnosis,

\footnotetext{
From the Department of Cardiac Surgery, Monroe Carell, Jr Children's Hospital, Vanderbilt University Medical Center, Nashville, Tenn.

Disclosures: The author reported no conflicts of interest.

The Journal policy requires editors and reviewers to disclose conflicts of interest and to decline handling or reviewing manuscripts for which they may have a conflict of interest. The editors and reviewers of this article have no conflicts of interest.

Received for publication Sept 26, 2021; revisions received Sept 26, 2021; accepted for publication Sept 28, 2021; available ahead of print Oct 1, 2021.

Address for reprints: David Bichell, MD, Monroe Carell, Jr Children's Hospital, Vanderbilt University Medical Center, 5247 Doctors' Office Tower, 2200 Children's Way, Nashville, TN 37232-9292 (E-mail: david.bichell@vumc.org).

J Thorac Cardiovasc Surg 2022;163:1642-3

0022-5223/\$36.00

Copyright (c) 2021 by The American Association for Thoracic Surgery

https://doi.org/10.1016/j.jtcvs.2021.09.047
}

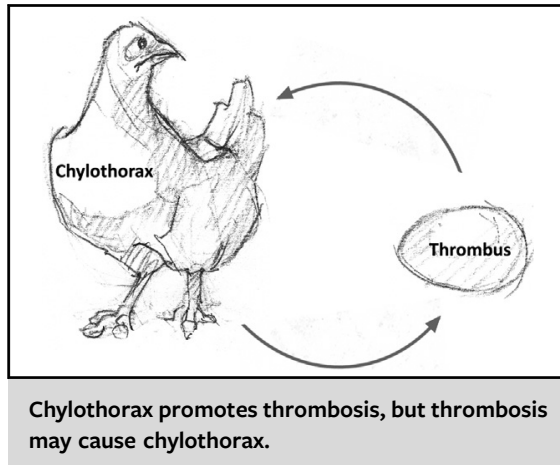

CENTRAL MESSAGE

Diagnostic limitations and circular associations of cause complicate the understanding of postoperative chylothorax. Propranolol is promising for treatment of those with intrinsic lymphatic pathology.

controversy over cause versus effect, and the determination of which culprit is behind a patient's chylothorax bedevils the accurate prediction of who will be a "responder" to therapies aimed at intrinsic lymph pathology.

\section{CHYLOTHORAX AS A CONSEQUENCE OF THROMBOSIS}

Borasino and colleagues ${ }^{2}$ demonstrated that postoperative chylothorax is strongly associated with percutaneous central venous line insertion in the upper body, suggesting that venous thrombosis as cause rather than consequence of chylothorax. Detection of thrombus in infants and children is poor by ultrasound ( $79 \%$ vs $34 \%$ sensitivity of venography vs ultrasound). A combination of ultrasound and venogram (seldom performed) is required for effective detection in the upper compartment. ${ }^{3}$ It is likely that central venous thrombosis is an underdiagnosed culprit in many cases of chylothorax.

\section{THROMBOSIS AS A CONSEQUENCE OF CHYLOTHORAX}

Bernet-Buettiker and colleagues ${ }^{4}$ demonstrated a significantly greater incidence of venous thrombosis in children suffering from postoperative chylothorax and a 2-fold greater concentration of antithrombin in chylous versus non-chylous effluent, postulating that thrombus formation 
may be a result of antithrombin losses into chylous drainage.

\section{THROMBOSIS AND CHYLOTHORAX AS CONSEQUENCES OF INTRINSIC COAGULOPATHY}

The concentrations of procoagulant and anticoagulant factors are significantly decreased in children with singleventricle physiology, who suffer an elevated risk of both thrombosis and chylothorax.

The circle of finger pointing between thrombosis, hemodynamics extrinsic to the lymphatics, intrinsic coagulopathy, and intrinsic lymphatic aberration as the cause of chylothorax remains to be resolved. Origin stories of thrombosis and chylothorax revolve in a chicken-versus-egg relationship. Impressive results in the propranolol-responsive group should prompt future investigations to understand factors that predict the individuals most likely to respond to this promising approach.

\section{References}

1. Corda R, Chrisomalis-Dring S, Crook S, Shawber CJ, Wu JK, Chai PJ. Propranolol treatment for chylothorax following congenital cardiac surgery. J Thorac Cardiovasc Surg. 2022;163:1630-41.e2.

2. Borasino S, Diaz F, Masri KE, Dabal RJ, Alten JA. Central venous lines are a risk factor for chylothorax in infants after cardiac surgery. World J Pediatr Congenit Hear Surg. 2014;5:522-6.

3. Male C, Chait P, Ginsberg JS, Hanna K, Andrew M, Halton J, et al. Comparison of venography and ultrasound for the diagnosis of asymptomatic deep vein thrombosis in the upper body in children results of the PARKAA study. Prophylactic Antithrombin Replacement in Kids with ALL treated with Asparaginase. Thromb Haemost. 2002;87:593-8.

4. Bernet-Buettiker V, Waldvogel K, Cannizzaro V, Albisetti M. Antithrombin activity in children with chylothorax. Eur J Cardiothorac. 2006;29:406-9.

5. Odegard KC, McGowan FX Jr, DiNardo JA, Castro RA, Zurakowski D Connor CM, et al. Coagulation abnormalities in patients with single-ventricle physiology precede the Fontan procedure. J Thorac Cardiovasc Surg. 2002;123: 459-65.
See Article page 1630.

\section{Commentary: Serendipity leads to a fresh idea for an old problem}

\author{
Dennis A. Wells, MD, and \\ David S. Winlaw, MBBS, MD
}

The authors introduce us to a novel pharmacologic approach to the highly relevant and sometimes challenging problem of postoperative chylothorax in congenital cardiac surgery patients. Although several case reports/series discuss use of propranolol for treatment of chylothorax in pediatrics, Corda and colleagues ${ }^{1}$ report the largest series to date detailing outcomes of propranolol treatment in pediatric cardiac surgery patients with chylothorax.

How did we get here and what is the mechanism by which propanolol reduces chylous drainage? Although the authors

\footnotetext{
From The Heart Institute, Cincinnati Children's Hospital Medical Center, Cincinnati, Ohio.

Disclosures: The authors reported no conflicts of interest.

The Journal policy requires editors and reviewers to disclose conflicts of interest and to decline handling or reviewing manuscripts for which they may have a conflict of interest. The editors and reviewers of this article have no conflicts of interest.

Received for publication Oct 1, 2021; revisions received Oct 1, 2021; accepted for publication Oct 1, 2021; available ahead of print Oct 6, 2021.

Address for reprints: David S. Winlaw, MBBS, MD, The Heart Institute, Cincinnati Children's Hospital Medical Center, 3333 Burnet Ave, MLC 2013, Cincinnati, OH 45229 (E-mail: David.winlaw@cchmc.org).

J Thorac Cardiovasc Surg 2022;163:1643-4

$0022-5223 / \$ 36.00$

Copyright (C) 2021 by The American Association for Thoracic Surgery

https://doi.org/10.1016/j.jtcvs.2021.10.001
}

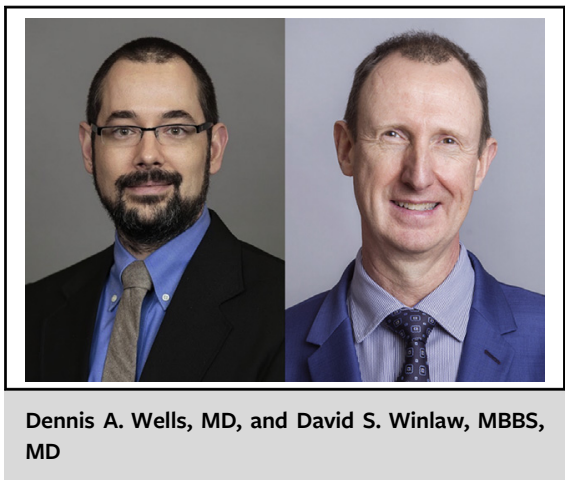

CENTRAL MESSAGE

Serendipity is an ally in medicine and can lead to fresh ideas for old clinical problems. Robust clinical trials of propanolol use in postoperative chylothorax are warranted.

provide a summary of scientific investigation into proposed mechanisms, they acknowledge that the mechanism by which propranolol reduces chylous drainage is unknown. It seems a series of events stemming from an episode of serendipity in France actually led to this proposition to 